Char asoff and Dintriev: An Anal yt i cal Char act er i sat i on of Ori gi ns of Li near Economi cs

\begin{tabular}{|l|l|}
\hline 著者 & Mor i Kenj i \\
\hline j our nal or & Di scussi on Paper s ( Tohoku Economics Research \\
publ i cat i on t i t l e & Group) \\
\hline year & 2010 - 01 \\
\hline URL & ht t p: //hdl . handl e. net /10097/55398 \\
\hline
\end{tabular}




\section{$\mathbb{T} \mathbb{E} \mathbb{R}$}

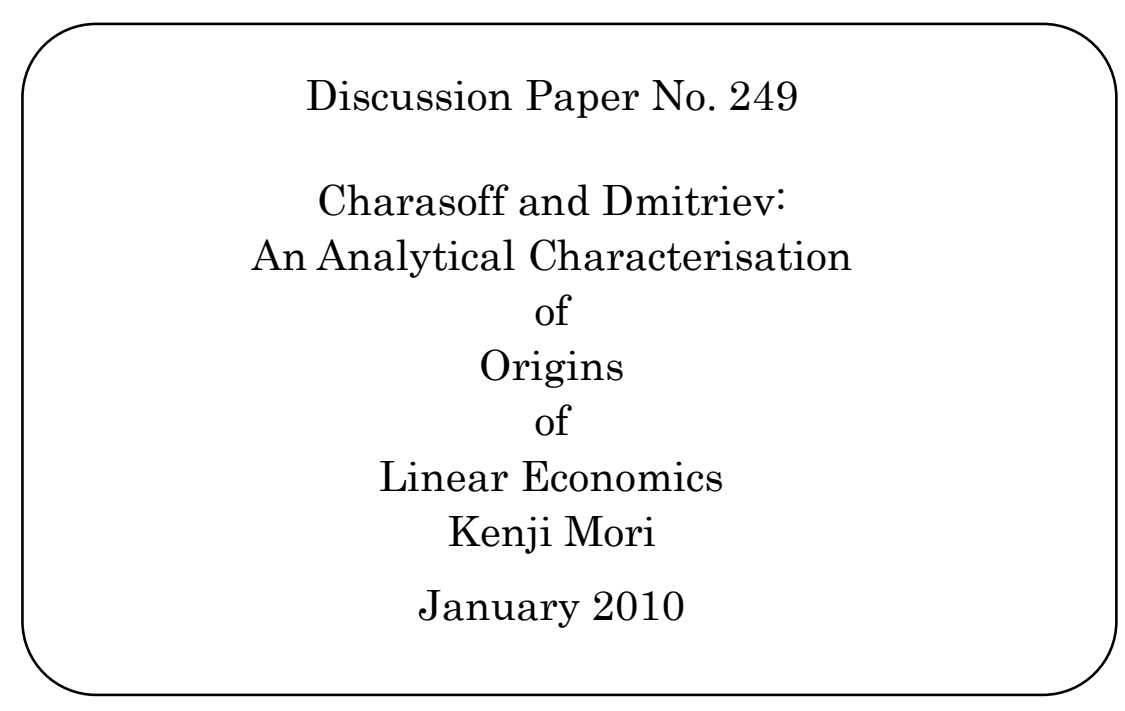

\section{TOHOKU ECONOMICS RESEARCH GROUP}

GRADUATE SCHOOL OF ECONOMICS AND MANAGEMENT TOHOKU UNIVERSITY KAWAUCHI, AOBA-KU, SENDAI, 980-8576 JAPAN 


\title{
Charasoff and Dmitriev: An Analytical Characterisation of Origins of Linear Economics
}

\author{
Kenji Mori \\ (Graduate School of Economics and Management,Tohoku University, Sendai, Japan)
}

\begin{abstract}
Georg von Charasoff was one of the first economic theorists to recognise that the price of production is an eigenvector of the input matrix, and to determine the rate of profit using its eigenvalue. $\mathrm{He}$ anticipated, at this analytical level, most of the arguments that were proposed later in the course of the 'transformation problem'. This paper aims to reformulate his significant arguments in a formal manner and to reveal their logical relationship by reproducing the mathematical reasoning, so that the logical characteristic of his system can be identified in comparison with Dmitriev's and Bortkiewicz's linear economic system.
\end{abstract}

Key words: Charasoff, Dmitriev, Bortkiewicz, Frobenius root, Fundamental Marxian Theorem

Address for correspondence: Graduate School of Economics and Management, Tohoku University, 27-1 Kawauchi, Aoba-ku, Sendai 980-8576, Japan. email: mori@econ.tohoku.ac.jp

\section{Introduction}

Since Georg von Charasoff ${ }^{1}$, a Russian mathematician and economist, was rediscovered more than 70 years after his main work, Das System des Marxismus. Darstellung und Kritik (1910), he has been acknowledged in many articles on the history of economic thought ${ }^{2}$ as a pioneer in linear economic theory and a forerunner of Leontief, Sraffa and von Neumann. However, reviewers tend to choose a part of his theory and point out its pioneering role; thus, his 'system' as a whole has not been fully examined ${ }^{3}$.

This paper aims to reformulate all the significant arguments of Das System des Marxismus in a more formal manner ${ }^{4}$ and to reveal their logical relationship by reproducing the mathematical reasoning that Charasoff must have had in mind when writing the book. We conclude the paper by comparing Charasoff's linear economic system with those of his predecessors, Dmitriev and Bortkiewicz.

The important elements of Charasoff's main argument are as follows:

1) The distinction between basic and non-basic products

2) The modelling of production price and general rate of profit using the eigenvector and eigenvalue 
of the input coefficients matrix, respectively

3) The duality of the price and quantity system (existence of a balanced growth path)

4) The 'fundamental theorem of Marxian profit theory' (the so-called Fundamental Marxian Theorem)

5) The convergence theorem for the Marxian transformation procedure from values to production prices

6) The theorem of rising rate of profit (the so-called Okishio Theorem)

Although the propositions in Charasoff's main work are discussed only in a narrative form and explained at most by numerical examples, his text allows every careful reader to unambiguously reproduce those formal proofs that the author must have had in mind.

\section{Charasoff's linear economic model and its essential condition}

\subsection{Definition of basic and non-basic products}

Charasoff introduced a distinction between basic products/production ('Grundproduktion') and subsidiary products/production ('Nebenproduction'). He defined basic production as production that 'reproduces its own means of production (including real wage) without others' assistance, and produces, in addition, the base of surplus production (i.e. subsidiary production)' (Charasoff, 1910, p. 81, parentheses added). Basic and non-basic products were understood in Sraffa's sense (Sraffa, 1960), and extended to 'augmented' inputs, i.e. basic products are used directly or indirectly in all sectors as factors of production (means of production and real wage). Non-basic products are used neither directly nor indirectly in at least one sector. According to Marx's distinction of social products, basic sectors correspond to Sectors I (means of production) and IIa (necessary means of subsistence), and non-basic sectors correspond to Sector IIb (luxuries). The definition of basic and non-basic products in Charasoff's sense can be reformulated as follows.

We first introduce the following symbols:

- input coefficient of good $i$ for Sector $j: a_{i j} \in \mathbf{R}_{+}$

- input coefficients matrix: $A:=\left(a_{i j}\right) \in M\left(n \times n, \mathbf{R}_{+}\right)$

- labour input coefficient for Sector $j: l_{j} \in \mathbf{R}_{+}$

- vector of labour input coefficients: $l:=\left(l_{1}, \cdots, l_{n}\right) \in \mathbf{R}_{+}^{n}$

- vector of real wage (wage basket) per labour unit: $d \in \mathbf{R}_{+}^{n}$

- augmented input coefficients matrix: $B=\left(b_{i j}\right):=A+d l \in M\left(n \times n, \mathbf{R}_{+}\right)$

- activity level of Sector $j: x_{j} \in \mathbf{R}_{+}$ 
- activity vector: $x^{\prime}:=\left(x_{1}, \ldots, x_{n}\right) \in \mathbf{R}_{+}^{n 5}$

- price of good $i: \quad p_{i} \in \mathbf{R}_{+}$

- price vector: $p:=\left(p_{1}, \cdots, p_{n}\right) \in \mathbf{R}_{+}^{n}$

- normalised price vector: $y=\left(y_{1}, \cdots, y_{n}\right):=\frac{1}{\sum_{i=1}^{n} p_{i}}\left(p_{1}, \cdots, p_{n}\right) \in Y ; Y:=\left\{y \in \mathbf{R}_{+}^{n} \mid \sum_{i=1}^{n} y_{i}=1\right\}$

- general rate of profit: $r \in \mathbf{R}$

Consider then the matrix $\sum_{t=1}^{n} B^{t}$. A good $i$ is a basic product ('Grundprodukt') if and only if the $i$-th row of this matrix is positive. Goods that are not basic products are non-basic products.

An equivalent definition can be given in the following manner. If $B$ is indecomposable, all $n$ goods are basic products. If $B$ is decomposable, it can be transformed into the following form by suitable simultaneous substitutions of rows and columns.

$B=\left(\begin{array}{cccc}B_{11} & B_{12} & \cdots & B_{1 n_{0}} \\ 0 & B_{22} & & \vdots \\ \vdots & & \ddots & \vdots \\ 0 & \cdots & 0 & B_{n_{0} n_{0}}\end{array}\right)$

where $B_{11}, \cdots, B_{n_{0} n_{0}}\left(n_{0}<=n\right)$ denote either a square null-matrix or a non-negative indecomposable square matrix. If $B_{11}$ is a null matrix, there is no basic product. Otherwise, choose, if possible, an index $i$ such that $b_{i i}$ is an element of $B_{11}$, and that for each $j=1, \ldots, n_{0},\left(\begin{array}{c}B_{1 j} \\ \vdots \\ B_{j-1 j}\end{array}\right) \geq 0$ if $B_{j j}$ is indecomposable and $\iota\left(\begin{array}{c}B_{1 j} \\ \vdots \\ B_{j-1 j}\end{array}\right)>0(\imath:=(1, \ldots, 1))$ if $B_{j j}$ is a null-matrix. Then, the good $i$ is a basic product ${ }^{6}$. Note that we use inequality signs for vectors and matrices in this paper so that $X>Y$, $X \geq Y$ and $X>=Y$ denote that $X-Y$ is positive, semi-positive and non-negative, respectively.

The distinction of basic and non-basic products plays two roles in the theoretical system proposed by 
Charasoff. First, it can falsify Marx's formula of production prices and the general rate of profit by providing an effective counterexample. Charasoff shows that the general rate of profit can be determined only for the basic sectors, and that luxuries are irrelevant to its determination. He then presents a numerical example where the general rate of profit deviated from the average among all sectors including a non-basic sector (Charasoff, 1910, pp. 93-104).

As we know, the idea of the determination of profit rate in the basic sectors can be traced back to Ricardo. Dmitriev first provided a formal expression, which was used by Bortkiewicz to falsify Marx's price formula three years before Charasoff (Bortkiewicz, 1907a, pp. 15-16; 1907b, pp. 323-24). Following Ricardian tradition, Dmitriev and Bortkiewicz, however, considered basic goods as wage goods and the inputs used to produce them directly and indirectly ${ }^{7}$. Charasoff generalised the category, apart from sticking to the relationship between wage goods and basic products, which is not logically necessary.

The second role of the distinction between basic and non-basic products in Charasoff's system is of a technical nature. It provides his price theory with a logical condition. In Charasoff's text, the distinction is assumed in such a simplified form that at least one basic product (e.g. a wage good) enters all sectors as direct input, and no non-basic products are used as input in any sector. This simplifying assumption is expressed in Assumptions (A.3), (A.4) and (A.5) in his model as reproduced in 1.2.1. Mathematically, these assumptions imply that the augmented input matrix has a simple Frobenius root that is the only eigenvalue of maximum modulus; this property is, as we will see, the condition that is essential to Charasoff's system and ensures in particular that the normalised power sequence ${ }^{8}$ of the augmented input matrix converges to a semi-positive matrix.

\subsection{Analysis of Charasoff's linear economic model}

\subsubsection{Assumptions}

Implicit in Charasoff's argument are several assumptions, which are as follows:

(A.1) Each production process produces a unique product, which means that the output coefficient matrix is an $n$-dimensional unit matrix.

(A.2) $A$ is productive, i.e. the Frobenius root of $A$ is less than unity.

(A.3) The real wage vector is semi-positive, i.e. $d \geq 0$.

(A.4) Labour is directly used in all sectors, i.e. $l>0$.

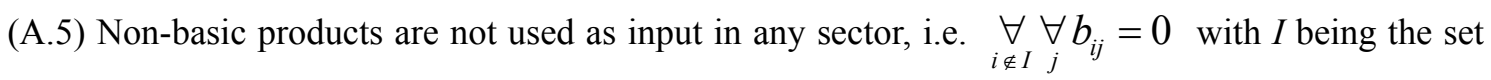
of indices of basic goods. 
It is useful to note the following: First, because, according to the Assumptions (A.3) and (A.4), labour is directly used in all sectors and real wage vector is semi-positive, $B$ has at least one positive row, say $i$. According to the definition, good $i$ is a basic product, and therefore the set of basic products is not empty.

Second, from (A.3), (A.4) and (A.5), it follows that, if a non-basic product exists, $A$ and $B$ have the following forms:

$$
\begin{aligned}
A & =\left(\begin{array}{cc}
A_{11} & A_{12} \\
0 & 0
\end{array}\right) \\
B & =\left(\begin{array}{cc}
B_{11} & B_{12} \\
0 & 0
\end{array}\right), \text { and } B_{11} \geq 0, B_{12} \geq 0
\end{aligned}
$$

If no non-basic products exist, we have $A=A_{11}, B=B_{11}$.

Third, the Assumptions (A.3), (A.4) and (A.5) as a whole are quite strong. They can be weakened in the following manner: the augmented input matrix $B$ should have a simple Frobenius root that is the only eigenvalue of maximum modulus ${ }^{9}$.

\subsubsection{Properties of the augmented input coefficients matrix}

Let $I:=\{1, \ldots, k\}, 1<=k<=n$ be the set of indices of basic products. Then, because of the form of $B$ in (1), all elements of the $(k+1)$-th to $n$-th row are null. The characteristic equation of $B$ is $t^{n-k}\left|t E-B_{11}\right|=0$ (where $E$ is the unit matrix). All eigenvalues of $B$ except $n-k$ noughts are therefore the same as those of $B_{11}$, and both matrices have the same multiplicity for each identical eigenvalue. Because $B_{11}$ is indecomposable according to the definition of the basic product, the Frobenius root of $B_{11}$ is the same as that of $B$ and a simple root of the characteristic equation of $B$. It is denoted as $\lambda_{0}$. Now, choose an index of good $i_{0}$ such that the $i_{0}$-th component of $d$ is positive (which is possible according to (A.3)). Then, the wage good $i_{0}$ is used in all sectors, particularly in Sector $i_{0}$. Therefore, at least one diagonal element of $B_{11}$ is positive, which implies that the matrix $B_{11}$ is primitive, i.e. the modulus of all eigenvalues of $B_{11}$ and $B$ except $\lambda_{0}$ is less than $\lambda_{0}$.

Next, we examine the eigenvectors of $B$ associated with $\lambda_{0}$. Because $B_{11}$ is indecomposable, we can choose a positive right-side eigenvector $u$ of $B_{11}$ and a positive left-side $\tilde{u}$ associated with the eigenvalue $\lambda_{0}$. Then, $v:=\left(u^{\prime}, 0\right)^{\prime}$ and $\tilde{v}:=\left(\tilde{u}, \tilde{u} B_{12} / \lambda_{0}\right)$ are right- and left-side eigenvectors of $B$ associated with $\lambda_{0}$, respectively, where $\tilde{u}>0, \quad \lambda_{0}>0$ and $\tilde{v}>0$. Because the eigen space of $B$ associated with $\lambda_{0}$ is one-dimensional, all right- and left-side eigenvectors associated with $\lambda_{0}$ are 
equal to $v$ and $\tilde{v}$, respectively, up to the scalar.

Now, define a matrix $\bar{B}$ as $\bar{B}:=B / \lambda_{0}$, and consider the limit of $\bar{B}^{t}$ for $t \rightarrow \infty$. As discussed above, the Frobenius root of $\bar{B}$ is unity and simple, and $v$ and $\tilde{v}$ are its right- and left-side eigenvectors, respectively. It is also clear that the modulus of all eigenvalues of $\bar{B}$ except for unity is smaller than unity. Therefore, for $t \rightarrow \infty, \bar{B}^{t}$ converges to a limit that is a semi-positive matrix. Considering $\bar{B}^{*}$ as the limit, we have:

$\bar{B}^{*}=\lim _{t \rightarrow \infty} \bar{B}^{t}=\lim _{t \rightarrow \infty} \bar{B}^{t+1}=\lim _{t \rightarrow \infty} \bar{B} \bar{B}^{t}=\bar{B} \bar{B}^{*}=\bar{B}^{*} \bar{B}$

We can see that each column and row of $\bar{B}^{*}$ is either a right- and left-side eigenvector of $\bar{B}$ associated with the Frobenius root, respectively, or the null vector. Therefore, there is a row vector $q \in \mathbf{R}_{+}^{n}$ such that

$\bar{B}^{*}=v q$

Because of $\tilde{v} \bar{B}=\tilde{v}$, we also have:

$\tilde{v}=\tilde{v} \bar{B}=\tilde{v} \bar{B}^{2}=\tilde{v} \bar{B}^{3}=\cdots=\tilde{v} \bar{B}^{*}$

From (2) and (3), we obtain:

$\tilde{v}=\tilde{v} \bar{B}^{*}=\tilde{v} v q$

Since $v \geq 0$ and $\tilde{v}>0, \tilde{v} v>0$. Then, from (2) and (4), we obtain:

$\bar{B}^{*}=v q=\frac{1}{\tilde{v} v} v \tilde{v}$

We can see that each column of $\bar{B}^{*}$ is the multiplication of the vector $v$ by a scalar, and that the proportion of the scalars to each other is equal to that of the components of $\tilde{v}$.

\section{Production price and general rate of profit}

After Charasoff effectively falsified Marx's price formula (Charasoff, 1910, pp.93-104), he then tried to formulate his own 'completely correct' price theory. To this end, he dedicated three chapters (VIII to X), which undoubtedly formed the climax of his book. The method of deduction of production prices is marked by his highly original ideas, represented by the notions 'production series', 'original capital' and 'dimensions', which characterise his theory as a whole. Formally speaking, his approach consists of finding the semi-positive eigenvector of the normalised augmented input matrix by 
deducing the convergence of its power sequence in the same manner as the Markov chain.

As we know, Dmitriev had, prior to Charasoff, proposed correct equations and provided a rational solution to determine the production prices. However, as shown in Section 7, the logical condition of his linear economic system does not coincide with that of Charasoff's system; therefore, the validity of each price equation is complementarily limited.

\subsection{Production series}

Let $X$ be an arbitrary bundle of goods and $X^{\prime}$ be the input for $X$, i.e. both the means of production used for the production of $X$ and the means of subsistence of labourers employed for the production of $X$. Similarly, let $X^{\prime \prime}$ be the input for $X^{\prime}$ and $X^{\prime \prime}$ ' be the input for $X^{\prime}$, etc. Charasoff called $X$ ' 'capital of the first order', $X$ " 'capital of the second order', etc. The sequence $X, X$ ', $X$ ”, $X$ ”' $\ldots$ was

called 'production series (Produktionsreihe)' of $X$. In order to confine his attention to the proportional composition, he normalised the capital of each order in that sequence and called the normalised composition the 'type (Typus)' of capital of each order. If we now introduce new symbols, $Z, Z$ ', $Z$ '”. for normalised $X, X^{\prime}, X^{\prime}$ '.., then we have a new sequence $Z, Z$ ',$Z$ ', $\ldots$ as a normalised 'production series' or sequence of 'types'.

\subsection{Original type and original capital}

Based on the above definitions, Charasoff deduced some important ideas that are representative of his theoretical system as a whole. They can be reformulated as follows.

Proposition 1. For any bundle of goods, the normalised production series converges to a common limit (See Appendix A.1).

The limit was called 'original type', and the capital that has the original type as its composition was called 'original capital'.

Let $E_{j}^{t}$ be the capital of the $t$-th order of product unit $j$ (i.e. the $(t+1)$-th term of the production series of product unit $j$ ), and $w_{j}^{t}$ be the sum of all components of $E_{j}^{t}$. Let $w^{t}$ be the vector $\left(w_{1}^{t}, w_{2}^{t}, \ldots, w_{n}^{t}\right)$, and $\bar{w}^{t}$ be the normalised $w^{t}$.

Lemma 1: For $t \rightarrow \infty, \bar{w}^{t}$ converges. 
Charasoff then called the $i$-th component of the limit the 'dimension' of product unit $i$. He then deduced the following from Proposition 1 and Lemma $1^{10}$ :

Proposition 2: The dimension of each product provides the normalised production price of this product.

Corollary 1: The original capital is produced using an original capital (i.e. the input of the original capital is an original capital).

Corollary 2: The rate of growth of the original capital provides the general rate of profit.

The above propositions are slightly replenished formalisations of the following original text of Charasoff.

'If $X$ is a certain commodity, and $X^{*}$ and $X^{* \prime}$ are capitals of two succeeding sufficiently high orders ..., then both capitals are of almost the same type (Proposition 1). Therefore, it follows that the original type to which all capitals of lower orders tend as their common limit has the property of growing without any qualitative change in the production process (Corollary 1). It follows that the rate of its growth must provide the general rate of profit (Corollary 2)'. The original capitals 'are all of the same composition, and therefore are no longer different from each other qualitatively; however, they differ quantitatively, i.e. only according to their dimensions (Lemma 1). They are different quantities of the same capital. ... and the production prices of their final products comply with these dimensions ...; therefore, their prices must be proportional to their dimensions (Proposition 2)' (Charasoff, 1910, pp. 124, 111, 123, parentheses added).

The analytical meanings of Proposition 2 and its corollaries are as follows: Considering the formula of production prices in the matrix form, i.e. $p=(1+r) p B$, Proposition 2 implies that the $n$-tuple of 'dimensions' of product units is a left-side eigenvector of the augmented input coefficients matrix $B$. On the other hand, Corollary 1 means that the original capital (original type) is a right-side eigenvector thereof. From Corollary 2, it follows that the general profit rate and the balanced growth rate can be calculated as dual phenomena of the same eigenvalue.

Indeed, Charasoff then tried to find a state in which all acquired profit is accumulated and all sectors grow in a common tempo, i.e. the state now known under the name of von Neumann's balanced 
growth. Charasoff obtained the same result as von Neumann did later, i.e. the equality of the rate of profit and growth.

'One should think of a capitalistic society where all surplus labour is directed to the accumulation or to the production of new capitals. At the same time, the accumulation process should be globally synchronised so that all enterprises grow annually in the same tempo, and all private entrepreneurs acquire a profit that is proportional to their capital and use it entirely for expanding their operation. Under these conditions, the social capital bears the original type, and the profit rate ... will provide the growth rate of the original capital in the process of the annual production' (Charasoff, 1910, pp. 126-7).

We paraphrase this content as follows:

Corollary 3: In case of balanced growth, the quantities of products in an economy bear the original type, and the general rate of profit equals the growth rate of the economy.

\section{3. 'Fundamental theorem of Marxian profit theory'}

Discovering the 'original capital' and the 'dimensions', Charasoff considered the price problem as 'finally solved'. He solved the price problem without considering labour value, contrary to the Marxian approach. However, he stated that it did not mean the bankruptcy of the labour theory of value (Charasoff, 1910, p.104). He was convinced that labour values ultimately regulate the prices (Charasoff, 1910, p.112). He then tried to base his price theory on Marx's value theory. This is said to occur in two ways: by the 'fundamental theorem of Marxian profit theory' (elsewhere, the 'fundamental theorem of Marxian surplus value theory') (Charasoff, 1910, pp. 13, 98) on the one hand, and on the other, by what is currently known as the convergence theorem for Marxian transformation procedure from values to production prices.

Using this 'fundamental theorem', Charasoff tried to 'prove the relationship between the level of profit rate and the provided surplus labour' explicitly (Charasoff, 1910, p. 104). His idea is as follows:

'If there is a profit for capitalists, then it can be explained as that the labour is sold under the value, or that the wage, as price of labour, falls short of the cost prices of labour -- i.e. the actual quantity of labour provided by the labourer. ... The main condition is and remains the disproportion between the wage and the actual provided labour', and 'this profit rate depends on the surplus labour because the ability of the original capital to grow in the production 
process and to provide a surplus is determined by surplus labour, i.e. by prolonging the working day over the necessary extent' (Charasoff, 1910, pp. 11-13, 112-13).

We reformulate his ideas as follows:

Proposition 3: The rate of profit is positive if and only if surplus labour is positive ${ }^{11}$.

We know that more than a half century had passed until this theorem was 'discovered' by Morishima and Seton (1961) and Okishio (1963) without any mention of Charasoff's prior contribution and was formalised under the name 'Fundamental Marxian Theorem' (Morishima, 1973, p. 53; Morishima and Catephores, 1978, p. 30 ${ }^{12}$. However, it is not claimed here that the first proof was provided by Charasoff, since it is also possible to assert that a de facto proof had already been provided by Dmitriev (Dmitiriev, 1904/1974, p.63, 77) ${ }^{13}$. However, Charasoff showed the equivalence of the positive exploitation and the positive profit rate by recognising the price vector as an eigenvector of the input coefficients matrix and determining the profit rate using the eigenvalue.

\section{Convergence theorem for Marxian transformation procedure}

As discussed in Section 3, Charasoff tried to base his price theory on the value theory in both ways. After discussing the 'fundamental theorem of Marxian profit theory', he then considered the convergence theorem for Marxian transformation procedure from values to production prices.

Marx's transformation procedure begins with considering labour values as initial prices and calculating the average of profit rates of all sectors to obtain the new prices. This is, however, only the first step of the transformation, and the obtained prices are the prices of the first order. Charasoff proceeded with the second step: re-calculating the cost prices according to the new prices and finding the intersectoral average of profit rates to obtain the prices of the second order. The same procedure should be repeated endlessly (Charasoff, 1910, pp. 134-39). If we normalise the prices of each order and call the normalised prices of the $k$-th order $p_{k}$, we can reformulate Charasoff's idea as follows:

Proposition 4 (convergence theorem for Marxian transformation procedure): $p_{k}$ converges and the limit provides production prices. At the same time, it is indifferent to the limit what kind of prices are taken as initial prices, especially whether the labour values are the initial prices (See Appendix A.3).

This proposition, as well as the convergence to the original type (Proposition 1), is based on the 
converging power sequence of the normalised augmented input matrix; therefore, the duality of both problems can be observed. Charasoff considered the iterated procedure stated above as Marx's own contribution. However, he saw it as a problem that Marx stopped continuing the procedure after the first step, and that Marx thought that he should begin with labour values as initial prices (Charasoff, 1910, p. 138).

Charasoff first showed the convergence of Marxian transformation procedure in the same manner as the Markov chain. Twenty-three years later, Shibata (1933) illustrated the convergence with a numerical example without referring to Charasoff, and Okishio $(1972,1973,1974)$ then provided a formal proof of the convergence theorem.

\section{Theorem of rising rate of profit}

It is well known that starting from Tugan-Baranowsky (1901) to Okisiho (1961), a series of major objections to Marx's law of the falling rate of profit were raised. While Tugan-Baranowsky falsified the law by providing counterexamples, Bortkiewicz, based on his price formula, proved that the profit rate must rise if a technical change lowers the cost price of at least one wage good (Bortkiewicz, 1907a). For Charasoff, the law means the negative part of Marxian theory which cannot be saved more even after his reconstruction. He brought forward two new points into the debate: first, a new cost criterion for the technical progress, i.e. an advanced production method lowers the cost price of the original capital (composed of basic products according to his assumptions) measured by the current prices. Second, he proved the theorem of the rising rate of profit by deducing implicitly the change (decrease) of the Frobenius root of the augmented input matrix.

'The general rate of profit is always intermediate among all partial profit rates that are calculated on the basis of an arbitrary price system' (Charasoff, 1910, p. 190).

By introducing a new production method, a capitalist can lower his cost price and raise his individual profit rate. Then, we have:

The new general rate of profit 'will lie between the profit rate R' of our capitalist and the profit rate $\mathrm{R}$ of all the other capitalists that are calculated on the basis of the old normal system. It can never fall under the earlier profit rate $\mathrm{R}$, and will always rise over this rate when the basic production is considered'. 'In order to obtain a falling rate of profit, we must assume a new mode of production that promises in advance a lower profit rate to the capitalists applying it' (Charasoff, 1910, pp. 190-192). 
We paraphrase this idea as follows:

Lemma 2: The general rate of profit lies always between the minimum and maximum among all individual profit rates that are calculated in terms of any arbitrary positive price system (See Appendix A.4).

Proposition 5: The general rate of profit rises if a new production method lowers the cost price of at least one component of the original capital in terms of the current prices, with the cost price of the other products remaining constant (See Appendix A.5).

\section{Calculation of labour value}

For proposing the 'fundamental theorem of Marxian profit theory', Charasoff had first assumed the existence of labour values and the well-defined rate of exploitation as given. In order to complete the proof, he dedicated chapter XII to the analysis of labour value.

Let $X$ be an arbitrary bundle of goods, and $X, X^{\prime}, X^{\prime \prime}, X^{\prime \prime \prime} \ldots$ be the production series of $X$. It is implicitly assumed here that the production technique is able to produce a surplus, i.e. the augmented input matrix is productive. Charasoff then called the series $X^{\prime}+X^{\prime \prime}+X^{\prime \prime \prime}+\ldots$, , 'reproduction capital' of $X$. The 'reproduction base' of $X$ is defined as the reproduction capital of $X$ obtained by neglecting labourers' subsistence.

Let $\bar{X}$ be the reproduction base of $X$. Then, Charasoff proposes the following (Charasoff, 1910, p. 147)

Proposition 6: The sum of labour used directly to produce $X+\bar{X}$ is the labour value of $X$ (See Appendix A.6).

It is easy to see that $X+\bar{X}$ is a series equivalent to $(E-A)^{-1} X$, and that Charasoff's value formula amounts to the well-known value equation $w=l(E-A)^{-1}$ ( $w$ and $E$ denote the labour-value vector and a unit matrix, respectively). However, it is Dmitriev, not Charasoff, who must be acknowledged as the originator of the value equation.

\section{Analytical characteristics of Charasoff's and Dmitriev's system}

It is claimed in this paper that the issues listed in the introduction comprise Charasoff's original contributions to linear economic analysis. On the other hand, as a matter of fact, we acknowledge 
that some of those topics had been addressed by Dmitriev and Bortkiewicz. However, because of the difference in their logical conditions, Charasoff's contributions cannot be absorbed into the achievement of his predecessors.

In general, the following achievements are considered as those of Dmitriev (see Nuti, 1974; Kurz \& Salvadori, 1995; Gehrke, 1998; Kurz \& Salvadori, 2000): determining the labour-value equation (Dmitriev, 1904/1974, pp. 44-45), formulating the price equation as the sum of the wage of dated labour and profit (Dmitriev, 1904/1974, p. 49), determining the necessary and sufficient condition for the equality between labour values and prices (i.e. the equality of 'organic composition of capital' in all sectors ${ }^{14}$ or $r=0$ ) (Dmitriev, 1904/1974, pp. 55-56, 71-73), formulating the reciprocal relation between wage and profit (Dmitriev, 1904/1974, p. 57), and determining the profit rate using price equations for wage goods (Dmitriev, 1904/1974, p. 59-61, 73). In addition, as mentioned in Section 3, he could prove the 'Fundamental Marxian Theorem' implicitly (see Appendix A.6). Based on Dmitriev's price equations, Bortkiewicz was able to provide a counterexample to Marx's formula of production prices by distinguishing basic products from non-basic products and prove the rising rate of profit following technical progress (see Appendix A.7).

We can, however, identify the essential condition of Charasoff's linear economic system, i.e. the condition of the system that distinguishes it from the system of his predecessors. It consists of the postulate that the augmented input coefficients matrix has a simple Frobenius root that is the only eigenvalue of maximum modulus. His assumption of basic and non-basic products in the simplified form, i.e. (A.3), (A.4) and (A.5), fulfils the essential condition as shown in 1.2.2.

On the other hand, the essential condition of Dmitriev's and Bortkiewicz's System is included in the postulate that the profit rate is lower than the so-called 'maximal profit rate' and the price of the wage basket is positive. That can be seen as follows. We know Dmitriev's price equation (Dmitriev, 1904/1974, p.49) as

$$
p=(1+r) p d \sum_{t=0}^{\infty} l A^{t}(1+r)^{t}
$$

By post-multiplying both sides by $d$ and cancelling them by $p d$, we obtain Dmitriev's equation of profit rate (Dmitriev, 1904/1974, p.60) as

$$
1=(1+r) \sum_{t=0}^{\infty} l A^{t}(1+r)^{t} d
$$

For the derivation of both the basic equations (6) and (7) of Dmitriev, which were taken over by 
Bortkiewicz (1907a, Formulas (20) and (30)), it must be postulated that the Frobenius root of $(1+r) A$ is less than unity (in other words, $r$ is less than the 'maximal rate of profit'), and that $p d$ is positive. These postulates can be therefore seen as the essential condition of their system.

Now, we can show that Dmitriev's and Bortkiewicz's assumption of the so-called 'Austrian' process fulfils these postulates. For their linear economic analysis, they assume explicitly that a series of dated labour is finite:

'ascending ever higher and higher to "production goods of higher orders" (the Productivgüter höherer Ordnung of the theoreticians of marginal utility), let us finally arrive at a capital good (or capital goods) produced solely by current labour' (Dmitriev, 1904/1974, pp. 53-54).

Just as suggested by the German words 'Productivgüter höherer Ordnung' and the reference to the marginal utility school, this property is named 'Austrian' by his reviewers (Kurz \& Salvadori, 1995; Gehrke, 1998; Kurz \& Salvadori, 2000).

First, the 'Austrian' process, i.e. a finite series of dated labour, can be formulated as follows:

$$
A^{n}=0 \text { and } l \sum_{t=0}^{n-1} A^{t}>0
$$

Then, $A^{n}=0$ implies that the Frobenius root of $A$, and therefore that of $(1+r) A$ is nought. On the other hand, $l \sum_{t=0}^{n-1} A^{t}>0$ implies that $\sum_{t=1}^{n} B^{t}=\sum_{t=1}^{n}(A+d l)^{t}$ has positive rows for all wage goods, which means that the wage goods are all basic products. If $B$ is decomposable, $B$ can be transformed by suitable simultaneous substitutions into the form shown in A.1.1, where $B_{11}$ is indecomposable and its columns involve all wage good sectors, and where $B_{22}, \cdots, B_{n_{0} n_{0}}$ are null matrices. As we can confirm, all semi-positive price vectors (left-side eigenvectors) with a well-defined profit rate have positive components for all basic products including wage goods. Therefore, we obtain $p d>0$.

Charasoff's essential condition and Dmitriev's (and Bortkiewicz's) do not coincide with each other; therefore, the price equation of one system has an unsolvable problem that the other is able to solve, as we can show by the numerical examples below. Correspondingly, the validity of the 'Fundamental Marxian Theorem' that was proved explicitly by Charasoff and implicitly by Dmitriev and 
Bortkiewicz and the theorem of rising rate of profit is limited to the specific area for which each system is able to provide a solution.

(i) Counterexample of Dmitriev's and Bortkiewicz's system

Set $A:=\left(\begin{array}{cc}\frac{1}{4} & \frac{1}{8} \\ 0 & \frac{1}{2}\end{array}\right), \quad l:=\left(\begin{array}{ll}1 & 1\end{array}\right), \quad$ and $\quad d:=\left(\begin{array}{c}\frac{1}{8} \\ 0\end{array}\right)$. Then, we have $B=\left(\begin{array}{cc}\frac{3}{8} & \frac{1}{4} \\ 0 & \frac{1}{2}\end{array}\right)$ and $\bar{B}=2 B=\left(\begin{array}{cc}\frac{3}{4} & \frac{1}{2} \\ 0 & 1\end{array}\right)$. According to Charasoff's procedure, we can show that $\lim _{t \rightarrow \infty} \bar{B}^{t}=\left(\begin{array}{ll}0 & 2 \\ 0 & 1\end{array}\right)$, and that $\left(\begin{array}{ll}0 & 1\end{array}\right)$ is the unique normalised semi-positive production price. The corresponding profit rate is unity $(100 \%)$. On the other hand, Dmitriev's equation of profit rate provides the unique solution $r=$ $5 / 3$. His price equation, however, cannot provide any meaningful solution, i.e. we could either have $p$

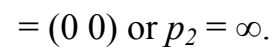

(ii) Counterexample of Charasoff's system

Set $A:=\left(\begin{array}{cc}0 & \frac{1}{2} \\ 0 & 0\end{array}\right), l:=\left(\begin{array}{ll}1 & 0\end{array}\right)$, and $d:=\left(\begin{array}{c}0 \\ \frac{1}{2}\end{array}\right)$. According to Dmitriev's equation of profit rate, we can show that the unique non-negative solution is $r=1$. Then, his price equation provides the unique normalised semi-positive production price $p=\left(\begin{array}{ll}0.5 & 0.5\end{array}\right)$. On the other hand, because $B=\left(\begin{array}{cc}0 & \frac{1}{2} \\ \frac{1}{2} & 0\end{array}\right)$ and $\bar{B}=2 B=\left(\begin{array}{ll}0 & 1 \\ 1 & 0\end{array}\right), \bar{B}$ is cyclic, and $\bar{B}^{t}$ does not converge; therefore, Charasoff's procedure cannot be applied to this example.

Even after relativising considerations mentioned above, we can indeed say as follows: Georg von Charasoff modelled the production prices and the general rate of profit de facto using the eigenvector and eigenvalue of the input matrix, and brought forward, on this analytical level, all significant arguments that were destined to be discussed in the course of the 'transformation problem'. In this sense, he can be seen as the initiator of mathematical Marxian economics. Considering that the Perron-Frobenius theorems were published no earlier than 1907/8, Charasoff excelled his contemporaries, Dmitriev and Bortkiewicz, in the sense that he could present all the relevant results on an algebraically advanced level on which just the following generation of linear production theory was going to discuss. 


\section{Appendix}

\section{A.1. Proof of Proposition 1}

Let $x \geq 0$ be an arbitrary vector of goods. $B^{t} x$ is the 'capital of the $t$-th order' of $x$ according to Charasoff's notation. The normalisation of $B^{t} x$ is the 'type' of capital of the $t$-th order of $x$. Next, normalise $B^{t} x$, and let $\left(B^{t} x\right)_{i}$ be the $i$-th component of the vector $B^{t} x$. Then, we have:

$$
\frac{1}{\sum_{i=1}^{n}\left(B^{t} x\right)_{i}} B^{t} x=\frac{1}{\sum_{i=1}^{n}\left(\lambda_{0}^{t} \bar{B}^{t} x\right)_{i}} \lambda_{0}^{t} \bar{B}^{t} x=\frac{1}{\sum_{i=1}^{n}\left(\bar{B}^{t} x\right)_{i}} \bar{B}^{t} x
$$

We can see that the normalisation of $B^{t} x$ and $\bar{B}^{t} x$ are identical. Because of (5), for $t \rightarrow \infty$, they converge to the following limit:

$$
\frac{1}{\sum_{i=1}^{n}\left(\bar{B}^{*} x\right)_{i}} \bar{B}^{*} x=\frac{1}{\sum_{i=1}^{n} v_{i}} v=: v^{*}
$$

Note that the limit $v^{*}$ is the normalised right-side eigenvector of $B$ associated with the Frobenius root, and that it is independent of $x$. Therefore, the limit is common to all bundles of goods and is called the 'original type' by Charasoff. (qed)

\section{A.2.Proof of Lemma 1}

The proof of Lemma 1 is provided in an analogous way to Proposition 1 because they can be seen as dual problems. The procedure of normalisation and convergence in (9) and (10) is now applied to the aggregation of rows instead of columns of $B^{t}$ in order to obtain:

$$
\lim _{t \rightarrow \infty} \bar{w}^{t}=\frac{1}{\sum_{j=1}^{n} \tilde{v}_{j}} \tilde{v}=: \tilde{v}^{*}
$$

\section{A3. Proof of Proposition 4}

Choose a normalised price vector $y_{0}>0$ arbitrarily (it can also be the labour-value vector). Let $x>0$ be an arbitrary activity vector. With $y_{0}$ being the current price system, $y_{0} B_{j}$ is the cost price of product unit $j$, and $y_{0}\left(E_{j}-B_{j}\right) / y_{0} B_{j}$ is the individual profit rate of Sector $j$, where $B_{j}$ and $E_{j}$ are the $j$-th column of $B$ and the unit matrix $E$, respectively. The individual profit rates need not be equal among the sectors. Calculating their weighted average $r_{0}$ according to the Marxian procedure, we 
have:

$r_{0}=y_{0}(E-B) x / y_{0} B x$

In the first step of the transformation procedure, we substitute all individual profit rates with the average rate $r_{0}$. We then obtain a new price vector $y_{1}$. After normalisation, it can be written as follows:

$y_{1}=\left(1+r_{0}\right) y_{0} B /\left(1+r_{0}\right) y_{0} B \iota=y_{0} B / y_{0} B \iota$

s.t. $l:=(1, \ldots, 1)$

With $y_{1}$ being the current price system, the individual profit rates need not be equal among the sectors. Calculating the average $r_{1}$, we have:

$r_{1}=y_{1}(E-B) x / y_{1} B x$

In the second step, we substitute all individual profit rates with the average $r_{1}$ to obtain a new (normalised) price system $y_{2}$ :

$y_{2}=y_{1} B / y_{1} B l=y_{0} B^{2} / y_{0} B^{2} \imath$

By following the same procedure, we obtain the price vector $y_{t}$ in the $t$-th step as follows:

$y_{t}=y_{t-1} B / y_{t-1} B \imath=y_{0} B^{t} / y_{0} B^{t} \iota$

According to (5), $y_{t}$ converges for $t \rightarrow \infty$ as follows:

$\lim _{t \rightarrow \infty} y_{t}=\lim _{t \rightarrow \infty} y_{0} \lambda_{0}^{-t} B^{t} / y_{0} \lambda_{0}^{-t} B^{t} \iota=\lim _{t \rightarrow \infty} y_{0} \bar{B}^{t} / y_{0} \bar{B}^{t} \iota=\tilde{v} / \tilde{v} \imath=\tilde{v}^{*}$

According to Lemma 1 and Proposition 2, this limit is a normalised production price. (qed)

\section{A.4. Proof of Lemma 2}

Choose a price vector $p>0$ arbitrarily. With $p$ being the current price system, $p B_{j}$ is the cost price of product unit $j$, and $p\left(E_{j}-B_{j}\right) / p B_{j}$ is the individual profit rate of Sector $j$. Let $r_{m}$ and $r_{M}$ be the lowest and highest individual profit rates, respectively. Then, we have:

$\frac{1}{1+r_{M}} p<=p B<=\frac{1}{1+r_{m}} p$

From $p v>0$, we obtain:

$\frac{1}{1+r_{M}} p v<=p B v=\lambda_{0} p v<=\frac{1}{1+r_{m}} p v$

$\frac{1}{1+r_{M}}<=\lambda_{0}<=\frac{1}{1+r_{m}}$ 
Because the general rate profit is $r=\frac{1}{\lambda_{0}}-1$, we obtain:

$r_{m}<=r<=r_{M}$

In particular, if the inequality in (12) is strict for a positive component of $v$, we obtain:

$r_{m}<r<r_{M} \quad$ (13) (qed)

\section{A.5. Proof of Proposition 5}

If a new production method is able to lower the cost price of at least one component of the original capital in terms of hitherto current prices, the individual profit rate of the sector producing it rises, while the individual profit rates of the other sectors remain constant. Let $p$ and $r$ be the hitherto current production prices and the hitherto current general rate of profit, respectively. Denote the new augmented input matrix as $\hat{B}$, the new right-side eigenvector of $\hat{B}$ associated with the Frobenius root as $\hat{v}$ and the new general rate of profit as $\hat{r}$. Assume that $v$ and $\hat{v}$ have positive values for the same sectors. By substituting $B$ and $r_{m}$ in (12) with $\hat{B}$ and $r$, respectively, the second inequality in (12) is valid and strict for the sector where the technical change occurs. Then, the first inequality in (13) is valid, which means that $r<\hat{r}$ in the present terms. (qed)

\section{A.6. Fundamental Marxian Theorem by Dmitriev}

By considering Dmitriev's equation of profit rate (7) and the assumption of the 'Austrian' process (8), we can show the following inequality in the case of $r>0$ :

$$
1=(1+r) \sum_{t=0}^{\infty} l A^{t}(1+r)^{t} d>\sum_{t=0}^{\infty} l A^{t} d=l(E-A)^{-1} d=w d>0
$$

On the other hand, $r<=0$ implies that

$$
1=(1+r) \sum_{t=0}^{\infty} l A^{t}(1+r)^{t} d<=\sum_{t=0}^{\infty} l A^{t} d=l(E-A)^{-1} d=w d
$$

Therefore, we can establish

$r>0 \Leftrightarrow \frac{1-w d}{w d}>0$

\section{A.7. The rising rate of profit by Bortkiewicz}

Assume that measuring by hitherto current prices, a technical change lowers the cost price of at least one wage good, while the other cost prices do not rise. Denote the new input coefficients matrix and labour coefficients vector as $\hat{A}$ and $\hat{l}$, respectively. In addition, assume that the assumption of the 'Austrian' process is valid for the new technology. According to Dmitriev's price equation (6), 
we obtain:

$1>(1+r) \sum_{t=0}^{\infty} \hat{l}^{t}(1+r)^{t} d$

Therefore, the new profit rate $\hat{r}$ that satisfies the following equation of profit rate must be higher than $r$.

$1=(1+\hat{r}) \sum_{t=0}^{\infty} \hat{l} \hat{A}^{t}(1+\hat{r})^{t} d$ 


\section{Notes}

${ }^{1}$ On Charasoff's biography and contemporary reception, see Mori (2007).

${ }^{2}$ See Egidi and Gilibert (1989); Kurz, 1989; Howard and King (1992); Kurz and Salvadori (1995, 1998, 2000); Egidi (1998); Stammatis (1999).

${ }^{3}$ As critical comments to the literature on Charasoff, we refer to Mori (2007).

${ }^{4}$ All propositions in Section 2 to 6 were first formulated in Mori (2007).

${ }^{5}$ Prime applied to matrices and vectors denotes, as usual, their transposition.

${ }^{6}$ To prove the equivalence of both the definitions, use the property of a non-negative

indecomposable $n \times n$ matrix $M: \sum_{t=1}^{n} M^{t}>0$.

${ }^{7}$ In Dmitriev's system, the profit rate is determined in the subsystem to which all wage goods belong. However, this subsystem does not need to be that of basic products. In a supplementary example where his basic assumption of the 'Austrian' process is suspended, Dmitriev himself illustrated a state in which the economy can be divided into two separate subsystems, in one of which the wage goods are used neither directly nor indirectly. See Dmitriev (1974, pp. 66-9).

${ }^{8}$ To be precise, this means the power sequence of the augmented input coefficient matrix divided by its Frobenius-root. By the normalised augmented input matrix, we mean the augmented input coefficient matrix divided by its Frobenius-root. We consider this terminology valid for the rest of this paper.

${ }^{9}$ To be sufficient for all propositions, $p v>0, p d>0$ and $w v>0$ must be additionally postulated.

${ }^{10}$ Proposition 2, Corollary 1, Corollary 2 and Corollary 3 follow obviously from Proposition 1 and

Lemma 1 because the vector of the dimensions $\tilde{v}^{*}$ and the original type $v^{*}$ are left-side and right-side eigenvectors of $B$ associated with the Frobenius root, respectively (see (10) and (11) in Appendix A.1 and A.2).

11 The proof of Proposition 3 can be also provided in a usual manner: i.e. considering that the gereral rate of profit is determined as $r=\frac{1}{\lambda_{0}}-1$, and using the equation $\lambda_{0} v=B v$ and the value equation $w=w A+l$, where $w>0$ is the vector of labour values (whose existence is proved in the proof of Proposition 6 given below). Because $w>0, v \geq 0, l>0, d \geq 0$ and therefore $w d l v>0$, we obtain:

$r>0 \Leftrightarrow 1-w d>0 \Leftrightarrow \frac{1-w d}{w d}>0$.

${ }^{12}$ Maurice Potron, a French mathematician, proved de facto Fundamental Marxian Theorem 48 years earlier than Morishima, Seton and Okishio by adapting the Perron-Frobenius theorems to economic problems, and he proved it by considering heterogeneous labours 65 years earlier and even more generally than Bowles and Gintis (1977, 1978). See Potron (1913) and Mori (2008).

${ }^{13}$ On the other hand, in his example, where the basic assumption of 'Austrian' process is suspended, Dmitriev stated that the profit could exist without any labour input in the economy (Dmitriev, 1974, pp. 63-66). This amounts to an invalidation of the theorem.

${ }^{14}$ According to Dmitriev's definition, the organic composition of capital is equal in all sectors if and only if $l A^{n}(n=0,1, \ldots$,$) are linearly dependent in pairs.$ 


\section{References}

Bortkiewicz, L.v. (1907a). Wertrechnung und Preisrechnung im Marxschen System. Zweiter und Dritter Artikel. Archiv für Sozialwissenschaft und Sozialpolitik, 25, 10-51, 445-488.

Bortkiewicz, L.v. (1907b). Zur Berechtigung der grundlegenden theoretischen Konstruktion von Marx im dritten Band des Kapitals. Jahrbücher für Nationalökonomie und Statistik, 34, 319-335.

Bowles S., Gintis H. (1977). The Marxian theory of value and heterogeneous labour: a critique and reformulation. Cambridge Journal of Economics, 1(2), pp. 173-192.

Bowles S., Gintis H. (1978). Professor Morishima on heterogeneous labour and Marxian value theory. Cambridge Journal of Economics, 2(3), pp.311-314.

Charasoff, G.v. (1910). Das System des Marxismus. Darstellung und Kritik, Berlin, Hans Bondy.

Dmitriev, V.K. (1974). Economic Essays on Value, Competition and Utility (D. Fry, Trans. and D.M. Nuti, Ed.). Cambridge University Press. (Original work published 1904)

Egidi M. (1998). Charasoff, Georg von. In Kurz H. and Salvadori N. (Eds), The Elgar Companion to Classical Economics( pp. 96-100). Cheltenham, Northampton: Elgar.

Egidi. M. and Gilibert, G. (1989). The Objective Theory of Prices. Political Economy: Studies in the Surplus Approach, 5, 59-74.

Gehrke, C. (1998). Charasoff, Dmitriev, Vladimir Karpovich. In Kurz H. and Salvadori N. (Eds), The Elgar Companion to Classical Economics (pp. 222-226), Cheltenham, Northampton: Elgar.

Howard, M.C. and King, J.E. (1992). A History of Marxian Economics: Volume II 1929-1990. Houndmills: Macmillan.

Kurz, H. (1989). Die deutsche theoretische Nationalökonomie zu Beginn des 20. Jahrhunderts zwischen Klassik und Neoklassik. In Schefold, B. (Ed.), Studien zur Entwicklung der ökonomischen Theorie (Vol. 8)(pp. 11-61). Berlin: Duncker und Humblot.

Kurz, H. and Salvadori, N. (1995). Theory of Production. A Long-Period Analysis. Cambridge University Press.

Kurz, H. and Salvadori, N. (1998). Von Neumann's Growth Model and the 'Classical' Tradition. In Kurz, H. and Salvadori, N. (Eds.), Understanding Classical Economics: Studies in Long-period Theory (pp. 25-56), London: Routledge.

Kurz, H. and Salvadori, N. (2000). 'Classical' Roots of Input-Output Analysis: a Short Account of its Long Prehistory. Economic Systems Research,12(2), 153-179.

Mori, K. (2007). Eine dogmenhistorische Dualität in der Reproduktions- und Preistheorie: Georg von Charasoff und Kei Shibata. Marx-Engels-Jahrbuch, 2006, 118-141.

Mori, K. (2008). Maurice Potron's linear economic model: a de facto proof of 'Fundamental Marxian Theorem'. Metroeconomica, 59(4), 511-529.

Morishima, M. (1973). Marx's Economics. A Dual Theory of Value and Growth. Cambridge 
University Press.

Morishima, M. and Catephores, G. (1978). Value, Exploitation and Growth: Marx in the Light of Modern Economic Theory. London, New York: McGraw-Hill.

Morishima, M. and Seton, F. (1961). Aggregation in Leontief matrices and the labour theory of value. Econometrica, 29(2), 203-220.

Nuti, D. M. 1974. Introduction. In Dmitriev (1904/1974).

Okishio, N. (1961). Technical Changes and the Rate of Profit. Kobe University Economic Review, 7, 85-99.

Okishio, N. (1963). A Mathematical Note on Marxian Theorems. Weltwirtschaftliches Archiv, 91, 287-299.

Okishio, N. (1972). Marx no seisankakakuron ni tsuite [On the Production Prices of Marx]. The Annals of Economic Studies (Kobe University), 19, 38-63.

Okishio, N. (1973). Marx no 'tenkei' tetsuzuki no shuusokusei [On the Convergence of Marx's 'Transformation' Procedure]. The Economic studies quarterly: The Journal of the Japan Association of Economics and Econometrics, 24(2), 40-45.

Okishio, N. (1974). Seisankakaku, heikinrijunritu [Price of Production and average rate of Profitrate]). pp. 23-46 In Tsuru, S. and Sugihara, S. (Eds.), Keizaigaku no gendaiteki kadai [Contemporary Issues of Economics]). Kyoto: Minerva.

Potron M. (1913). 'Quelques propriétés des substitutions linéaires à coefficients $>=0$ et leur application aux problèmes de la production et des salaires. Annales scientifiques de l'É.N.S. 3e série, 30, 53-76.

Shibata, K. (1933). The Meaning of the Theory of Value in Theoretical Economics. Kyoto University Economic Review, 8(2), 49-68.

Sraffa, P. (1960). Production of Commodities by Means of Commodities. A Prelude to a Critique of Economic Theory. Cambridge University Press.

Tugan-Baranowsky, M.v. (1901). Studien zur Theorie und Geschichte der Handelskrisen in England. Jena: Fischer. 